\title{
Reversal of Phencyclidine-Induced Hyperactivity by Glycine and the Glycine Uptake Inhibitor Glycyldodecylamide
}

Daniel C. Javitt, M.D., Ph.D., Henry Sershen, Ph.D., Audrey Hashim, M.S., Abel Lajtha, Ph.D.

Phencyclidine (PCP) induces a psychotic state that closely resembles schizophrenia. In preclinical studies, PCP has been shown to induce its unique behavioral effects by blocking excitatory neurotransmission mediated at the $\mathrm{N}$-methyl-D-asparate (NMDA) receptors, suggesting that agents which potentiate NMDA receptor-mediated neurotransmission might have clinically beneficial effects. The present study demonstrates that the NMDA co-agonist glycine inhibits rodent hyperactivity induced by $P C P$, but not amphetamine. Glycyldodecylamide, a compound that blocks neuronal glycine uptake and which may therefore increase intrasynaptic glycine levels, inhibits PCP-induced hyperactivity more potently than glycine. These results complement recent clinical studies with glycine and suggest that glycine-uptake inhibitors, as well as glycine, may be beneficial in the treatment of PCP-induced psychosis and schizophrenia. [Neuropsychopharmacology 17:202204, 1997] (C) 1997 American College of Neuropsychopharmacology. Published by Elsevier Science Inc.
KEY WORDS: Excitatory amino acids; NMDA receptors; Rodent; Drug abuse; Negative symptoms; Schizophrenia

Phencyclidine (PCP) induces a psychotic state that closely resembles schizophrenia, most likely by blocking neurotransmission mediated at $N$-methyl-D-aspartate (NMDA)-type glutamate receptors (reviewed in Javitt and Zukin 1991). Further, other NMDA antagonists (e.g., ketamine) also induce negative and cognitive symptoms similar to those of schizophrenia (Krystal et al. 1994) and rekindle presenting symptoms in remitted schizophrenic subjects (Lahti et al. 1995), indicating that endogenous NMDA receptor dysfunction may contribute significantly to the pathophysiology of schizophrenia.

From the Nathan Kline Institute for Psychiatric Research, Orangeburg, New York.

Address correspondence to: Daniel C. Javitt, M.D., Ph.D., Director, Program in Cognitive Neuroscience and Schizophrenia, Nathan Kline Institute for Psychiatric Research, 140 Old Orangeburg Road, Orangeburg, NY 10962.

Received January 27, 1997; revised March 10, 1997; accepted March 18, 1997.
NMDA receptors contain binding sites for several modulatory compounds including glycine and polyamines. Binding of glycine to its modulatory site enhances NMDA receptor activation, indicating a potential role for glycine in the treatment of schizophrenia. In recent clinical studies, administration of 30-60 g/day $(0.4-0.8 \mathrm{~g} / \mathrm{kg} /$ day) of glycine was found to induce significant amelioration of negative and cognitive symptoms (reviewed in Heresco-Levy et al. 1996). These doses are known to significantly elevate CNS glycine levels (D'Souza et al. 1995). Similar results have been obtained with the partial glycine agonist D-cycloserine (Goff et al. 1995). The potential usefulness of glycine for the treatment of schizophrenia has also been supported by studies demonstrating that glycine, but not other amino acids, significantly inhibited PCP-induced hyperactivity in rodents (Toth and Lajtha 1986). In those studies, several glycine derivatives were found to effectively reverse PCP-induced hyperactivity, the most potent of which was glycyldodecylamide (GDA) (Toth et al. 1986). Unlike glycine and other glycine derivatives, GDA treatment was found not to increase whole brain 
glycine levels, indicating that it was not functioning primarily as a glycine precursor. Recently, it has been demonstrated that GDA also does not bind to the NMDA-associated glycine binding site. However, GDA does antagonize synaptosomal glycine uptake by blocking glycine transport mediated by the "gly" transport
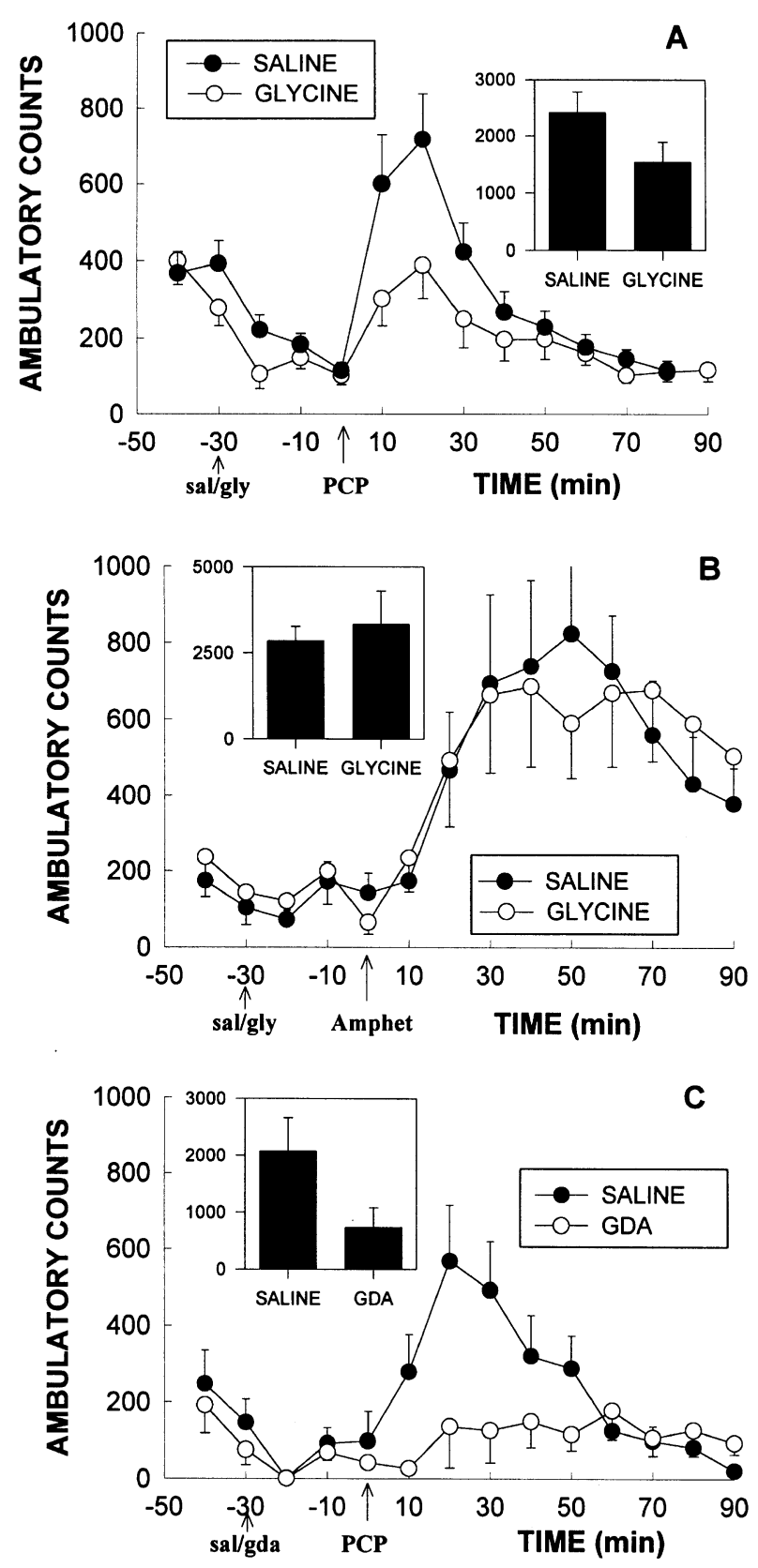

Figure 1. Effect of pretreatment with glycine (gly, $0.8 \mathrm{~g} / \mathrm{kg}$ i.p.) or saline (sal) on hyperactivity induced by either (A) phencyclidine (PCP, $5 \mathrm{mg} / \mathrm{kg}$ i.p.) or (B) amphetamine (amphet, $5 \mathrm{mg} / \mathrm{kg}$ i.p.). Data are mean \pm s.e.m. (C) Effect of glycyldodecylamide (GDA) on PCP-induced hyperactivity. Inset figures show integrated activity over 0-60 minutes following PCP or amphetamine administration from the illustrated experiment. system (Javitt and Frusciante 1996). The "gly" system is a major regulator of extracellular glycine levels in brain. Moreover, an isoform of the GLYT1 transporter, which mediates gly system transport, is colocalized with NMDA receptors (Smith et al. 1992). Thus, GLYT1 transporter-mediated uptake might function in part to maintain low synaptic glycine levels in the immediate vicinity of NMDA receptors. Inhibition of these transporters would raise glycine concentrations in the immediate vicinity of NMDA receptors by redistributing intra- and extracellular glycine without, necessarily, increasing whole brain glycine levels.

Although effects of glycine and GDA were first reported more than a decade ago, the finding that these agents inhibit PCP-induced hyperactivity following peripheral injection has not been confirmed. Moreover, the specificity of their effect has not been investigated. In particular, the possibility that they function by inducing nonspecific sedation or motor incoordination through interaction with hindbrain glycine receptors must be considered. The present study investigates effects of glycine and GDA on PCP-induced hyperactivity using a paradigm similar to that used previously (Toth et al. 1986; Toth and Lajtha 1986). Moreover, potential non-specific effects of glycine are evaluated by investigating its effects on locomotor hyperactivity induced by amphetamine, a psychomotor stimulant that functions by modulating dopaminergic, rather than glutamatergic, neurotransmission.

GDA was synthesized in accordance with the methods of Toth et al. (1986). Residual glycine was found to be $<0.1 \%$. Rodent activity was monitored using a photocell-based activity meter (Columbus Instruments AutoTrack System, Columbus, OH). Animals were placed in test cages and allowed to accommodate overnight. On the day of experiment, animals, in their home cages,

Table 1. Effect of glycine and glycyldodecylamide GDA on PCP- and amphetamine-induced locomotor hyperactivity

Treatment/pretreatment

Integrated activity $0-60 \mathrm{~min}$.

\begin{tabular}{|c|c|}
\hline Treatment/pretreatment & mean \pm s.d. (n) \\
\hline Control & $151 \pm 121(8)$ \\
\hline \multicolumn{2}{|l|}{ РСР (5 mg/kg) } \\
\hline + saline & $2364 \pm 1736(48)$ \\
\hline+ glycine $(0.8 \mathrm{~g} / \mathrm{kg})^{*}$ & $1491 \pm 1497(24)$ \\
\hline+ GDA $(0.01 \mathrm{~g} / \mathrm{kg})$ & $2551 \pm 1764(8)$ \\
\hline + GDA $(0.05 \mathrm{~g} / \mathrm{kg})$ & $1535 \pm 1569(8)$ \\
\hline+ GDA $(0.1 \mathrm{~g} / \mathrm{kg})^{*}$ & $732 \pm 980(8)$ \\
\hline \multicolumn{2}{|l|}{ Amphetamine $(2 \mathrm{mg} / \mathrm{kg})$} \\
\hline + saline & $849 \pm 462(8)$ \\
\hline + glycine $(0.8 \mathrm{~g} / \mathrm{kg})$ & $1008 \pm 1231(8)$ \\
\hline \multicolumn{2}{|l|}{ Amphetamine (5 mg/kg) } \\
\hline + saline & $2854 \pm 1860(12)$ \\
\hline + glycine $(0.8 \mathrm{~g} / \mathrm{kg})$ & $3336 \pm 3356(12)$ \\
\hline
\end{tabular}

${ }^{*} p<.05$ vs. saline. 
were placed on the activity monitors and baseline activity was monitored for 20 minutes, after which time animals were pretreated with either saline, glycine $(0.8 \mathrm{~g} / \mathrm{kg}$ intraperitoneally (i.p.)) or GDA (0.01-0.1 g/ kg i.p.). Thirty minutes after pretreatment, animals were injected with either PCP $(5 \mathrm{mg} / \mathrm{kg}$ i.p.) or amphetamine (5 $\mathrm{mg} / \mathrm{kg}$ subcutaneously (s.c.)). Activity was then monitored for an additional 90 minutes. For statistical analyses, summed activity over the 60 minutes following $\mathrm{PCP} /$ amphetamine injection was used as a measure of drug-induced hyperactivity.

Both PCP (Figure 1A) and amphetamine (Figure 1B) induced robust behavioral activation with the degree of activation produced by $5 \mathrm{mg} / \mathrm{kg}$ amphetamine being similar to that induced by $5 \mathrm{mg} / \mathrm{kg} \mathrm{PCP}$, albeit longer in duration. Despite the similarity in overall activation levels induced by the two agents, glycine-induced inhibition of activation differed between the two treatments. Glycine led to a significant reduction of PCPinduced hyperactivity to approximately $60 \%$ of control value (Table 1). In contrast, no significant effect of glycine was observed on amphetamine-induced hyperactivity. GDA induced a significant dose-dependent inhibition of PCP-induced hyperactivity. The degree of reduction induced by $0.05 \mathrm{~g} / \mathrm{kg}$ GDA was similar to that induced by $0.8 \mathrm{~g} / \mathrm{kg}$ glycine, indicating 16 -fold greater potency. The degree of behavioral inhibition induced by 0.05 and $0.1 \mathrm{~g} / \mathrm{kg}$ of GDA is similar to that reported previously (Toth et al. 1986).

The present results confirm previous reports concerning the effectiveness of both glycine and GDA in inhibiting PCP-induced hyperactivity, and demonstrate that a dose of glycine that significantly inhibits PCPinduced hyperactivity does not inhibit hyperactivity induced by the dopaminergic agent amphetamine. To the extent that GDA functions as a glycine uptake inhibitor in vivo, these findings support the concept that glycine uptake inhibitors as a group may be more effective than glycine itself in reversing symptoms of PCP psychosis and schizophrenia. Glycine uptake antagonists with high potency and selectivity, however, must be developed before the potential usefulness of such agents in the treatment of PCP psychosis and schizophrenia can be definitively determined. The observation that glycine does not inhibit amphetamine-induced hyperactivity indicates that its antagonistic effects on PCP-induced hyperactivity cannot be accounted for by nonspecific effects such as sedation or incoordination. PCP induces its behavioral effects primarily by blocking NMDA receptors. PCP-induced NMDA blockade, in turn, leads to increased subcortical dopamine release which may mediate the hyperactivity induced by PCP and other NMDA antagonists. In contrast, amphetamine induces hyperactivity by directly stimulating dopamine release. The differential effect of glycine on PCP- versus am- phetamine-induced hyperactivity may therefore be due to the fact that the locus of amphetamine effects are "downstream" from the NMDA receptor. Overall, the present findings support the need for continued development of NMDA potentiating agents for potential treatment of PCP-induced behavioral syndromes and schizophrenia.

\section{ACKNOWLEDGMENTS}

This work was supported by NIDA research grant \#R01 DA03383 and grants from the Theodore and Vada Stanley Foundation and Zara and Bernad Jakubovitz Fund for Brain Research to DCJ.

\section{REFERENCES}

D'Souza DC, Charney D, Krystal J (1995): Glycine site agonists of the NMDA receptor: a review. CNS Drug Rev $1: 227-260$

Goff DC, Tsai G, Manoach DS, Coyle JT (1995): Dose-finding trial of $D$-cycloserine added to neuroleptics for negative symptoms in schizophrenia. Am J Psychiatry 152:12131215

Heresco-Levy U, Silipo G, Javitt DC (1996): Glycinergic augmentation of NMDA receptor-mediated neurotransmission in the treatment of schizophrenia. Psychopharmacol Bull 32:731-740

Javitt DC, Frusciante M (1997): Glycyldodecylamide, a phencyclidine behavioral antagonist, blocks cortical glycine uptake: Implications for schizophrenia and substance abuse. Psychopharmacol 129:96-98

Javitt DC, Zukin SR (1991): Recent advances in the phencyclidine model of schizophrenia. Am J Psychiatry 148: 1301-1308

Krystal JH, Karper LP, Seibyl JP, Freeman GK, Delaney R, Bremner JD, Heninger GR, Bowers MBJ, Charney DS (1994): Subanesthetic effects of the noncompetitive NMDA antagonist, ketamine, in humans. Psychotomimetic, perceptual, cognitive, and neuroendocrine responses. Arch Gen Psychiatry 51:199-214

Lahti AC, Koffel B, LaPorte D, Tamminga CA (1995): Subanesthetic doses of ketamine stimulate psychosis in schizophrenia. Neuropsychopharmacology 13:9-19

Smith KE, Bordon LA, Hartig PR, Branchek T, Weinshank RL (1992): Cloning and expression of a glycine transporter reveal colocalization with NMDA receptors. Neuron 8:927-935

Toth E, Lajtha A (1986): Antagonism of phencyclidineinduced hyperactivity by glycine in mice. Neurochem Res 11:393-400

Toth E, Weiss B, Banay-Schwartz M, Lajtha A (1986): Effect of glycine derivatives on behavioral changes induced by 3-mercaptopropionic acid or phencyclidine in mice. Res Comm Psychol Psychiat Behav 11:1-9 